\title{
小麦穗发芽性状的全基因组关联分析
}

\author{
谢 䂞 1,2 任 毅 ${ }^{1,2}$ 张新忠 1,3 王继庆 ${ }^{1,2}$ 张志辉 1,2 石书兵 ${ }^{1,2}$ \\ 耿洪伟 $1,2, *$
}

${ }^{1}$ 新疆农业大学农学院, 新疆乌鲁木齐 $830052 ;^{2}$ 新疆农业大学生物技术重点实验室, 新疆乌鲁木齐 $830052 ;{ }^{3}$ 新疆农业科学院粮食 作物研究所, 新疆乌鲁木齐 830091

摘 要: 为了解小麦穗发芽的遗传机制, 发掘与小麦穗发芽相关的候选基因, 采用整穗发芽法对来自全国的 207 份 小麦品种(系)进行表型鉴定, 并结合小麦 90K SNP 基因芯片, 通过 TASSLE 软件的 MLM (Q+K)模型对小麦的整穗发 芽率进行全基因组关联分析(genome-wide association study, GWAS)。研究结果表明, 不同年份间小麦品种(系)的穗发 芽表现出丰富的表型变异, 变异系数为 0.34 和 0.25 , 多态性信息含量 (polymorphic information content, PIC)为 $0.01 \sim 0.38$, 全基因组 LD 衰减距离为 $3 \mathrm{Mb}$ 。群体结构分析和主成分分析表明, 207 份小麦品种(系)所构成的自然群体 结构简单, 可分为 3 个亚群。GWAS 检测结果显示, 在不同环境间共检测到 34 个与小麦穗发芽显著关联的 SNP 标记 位点 $(P \leqslant 0.001)$, 分布在小麦 $3 \mathrm{~A} 、 3 \mathrm{~B} 、 4 \mathrm{~A} 、 4 \mathrm{~B} 、 5 \mathrm{D} 、 6 \mathrm{~A} 、 6 \mathrm{~B} 、 6 \mathrm{D} 、 7 \mathrm{~B}$ 和 $7 \mathrm{D}$ 染色体上, 单个位点可解释 $5.55 \% \sim 11.63 \%$ 的表型变异, 16 个标记位点在两个及以上环境下均被检测到, 其中 6B 染色体上的标记 wsnp_Ex_c14101_22012676 在 E1、E2 及平均环境下被共同检测到, 属稳定遗传的位点。通过对表型效应值大且稳定遗传的关联位点进行挖掘, 共 䇛选到 13 个与小麦穗发芽相关的候选基因。其中 TraesCS3A01G589400LC、TraesCS6B01G138600/TraeCS6B01G516 700LC/TraesCS6B01G548900LC、TraesCS6D01G103600 及 TraesCS7B01G200100 等基因通过调控植物内源激素-脱落 酸 (abscisic acid, ABA) 的灵敏性进而影响种子的休眠; TraesCS3B01G415900LC、TraesCS6A01G144700LC 及 TraesCS6B01G294800 等基因编码的 F-box 蛋白在植物激素的信号转导、光信号转导以及花器官发育等生理过程中起 重要作用; TraesCS6A01G108800、TraesCS6B01G138200/TraesCS6B01G293700 基因编码 Myb 转录因子家族蛋白能调 控种子中类黄酮的生物合成，对籽粒颜色有重要影响，这些候选基因是与小麦穗发芽相关的重要基因。

关键词：小麦; 穗发芽; 全基因组关联分析; SNP; 候选基因

\section{Genome-wide association study of pre-harvest sprouting traits in wheat}

XIE Lei ${ }^{1,2}$, REN Yi $^{1,2}$, ZHANG Xin-Zhong ${ }^{1,3}$, WANG Ji-Qing ${ }^{1,2}$, ZHANG Zhi-Hui ${ }^{1,2}$, SHI Shu-Bing ${ }^{1,2}$, and GENG Hong-Wei ${ }^{1,2, *}$

\footnotetext{
${ }^{1}$ Agricultural College of Xinjiang Agricultural University, Urumqi 830052, Xinjiang, China; ${ }^{2}$ Key Laboratory of Biotechnology, Xinjiang Agricultural University, Urumqi 830052, Xinjiang, China; ${ }^{3}$ Institute of Grain Crops, Xinjiang Academy of Agricultural Sciences, Urumqi 830091, Xinjiang, China
}

\begin{abstract}
To understand the genetic mechanism of wheat pre-harvest sprouting (PHS) in wheat breeding, it is significant to explore marker loci and candidate genes associated with PHS resistance using intact spikes. In this study, a total of 207 wheat varieties (lines) from China and 16,686 SNP markers were analyzed in wheat whole genome. The mixed liner model (Q + K) was used to analyze PHS phenotypic data in three environments. Genome-wide association study showed that there were abundant phenotypic variations in different environments and wheat varieties (lines). The coefficient of variation was 0.34 and 0.25 , the polymorphic information content of value (PIC) was from 0.01 to 0.38 , and the attenuation distance of whole genome LD was 3
\end{abstract}

本研究由国家自然科学基金项目(31771786)和新疆维吾尔自治区科技创新基地建设项目(PT1910)资助。

This study was supported by the National Natural Science Foundation of China (31771786) and the Technical Innovation Bases Construction Project of Xinjiang Uygur Autonomous Region (PT1910).

*通信作者(Corresponding author): 耿洪伟, E-mail: hw-geng@163.com

第一作者联系方式: E-mail: 1784462634@qq.com

Received (收稿日期): 2020-10-04; Accepted (接受日期): 2021-01-13; Published online (网络出版日期): 2021-02-24.

URL: https://kns.cnki.net/kcms/detail/11.1809.S.20210223.1702.006.html 
$\mathrm{Mb}$. The population structure and principal component analysis revealed that 207 wheat varieties (lines) could be divided into three subgroups. GWAS results indicated that 34 SNP markers were detected, which were significantly associated with pre-harvest sprouting at $P<0.001$. They were located on chromosomes 3A, 3B, 4A, 4B, 5D, 6A, 6B, 6D, 7B, and 7D, and each explained $5.55 \%-11.63 \%$ of phenotypic variation. There were 16 markers loci detected in more than two environments, and the marker Np_Ex_c14101_22,012,676 on 6B chromosome detected in E1, E2, and average environment. Meanwhile, 13 candidate genes were screened out by mining association loci with large phenotypic effect value and stable inheritance. TraesCS3A01G589400LC, TraesCS6B01G138600/TraesCS6B01G516700LC/TraesCS6B01G548900LC, TraesCS6D01G103600, and TraesCS7B01G200100 could affect seed dormancy by regulating the sensitivity of endogenous ABA in plants. The F-box proteins were encoded by TraesCS3B01G415900LC, TraesCS6A01G144700LC, and TraesCS6B01G294800, which played major roles in plant hormone signal transduction, light signal transduction, and flower organ development. TraesCS6A01G108800, TraesCS6B01G138200/ TraesCS6B01G293700 encoded Myb transcription factor family. These candidate genes are important genes related to wheat sprouting.

Keywords: wheat; pre-harvest sprouting; genome-wide association analysis; SNP; candidate gene

小麦是我国乃至世界最重要的粮食作物之一, 其产量与品质备受关注 ${ }^{[1-2]}$ 。近年来, 随着全球气候 变暖以及极端天气频发, 小麦成熟至收获期间穗上 发芽现象越发频繁, 严重降低小麦产量, 劣化小麦 品质, 穗发芽已成为全球性危害 ${ }^{[3]}$ 。穗发芽促使籽粒 内部水解酶活性增加, 籽粒内部储藏物质被分解消 耗, 从而造成籽粒容重和千粒重下降, 导致小麦减 产 ${ }^{44]}$ 。同时，由于蛋白质被降减，小麦制粉后的 SDS 沉降值和面筋含量逐渐降低, 用发芽小麦粉加工的 面制品如馒头、面包等, 外形和口感较差, 严重影响 其营养品质和加工品质 ${ }^{[5-6]}$ 。全球每年因穗发芽而造 成的直接经济损失约 10 亿美元 ${ }^{[7]}$ 。培育抗穗发芽小 麦新品种是解决这一问题最有效的途径之一。

小麦穗发芽是受种子休眠水平、种子结构、种 皮颜色等内部因素以及温度、湿度、光照等外界环 境因素共同作用的结果 ${ }^{[8-9]}$ 。种子的休眠特性是影响 小麦穗发芽抗性的主要遗传因素 ${ }^{[10]}$ 。目前对于小麦 穗发芽鉴定的方法主要有籽粒发芽法、整穗发芽法 和 $\alpha$-淀粉酶活性测定法 ${ }^{[10]}$ 。籽粒发芽主要反映小麦 籽粒的休眠情况, 并不能表现出颖壳、麦芒等抑制 物的作用 ${ }^{[10]}$ 。 $\alpha$-淀粉酶活性测定可以鉴定胚乳抑制 物对穗发芽的影响, 但操作复杂, 不适合进行批量 化测定 ${ }^{[11]}$ 。整穗发芽不仅能综合性反映小麦穗发芽 的抗性, 而且操作简单, 适合批量化测定, 因此常 用来鉴定小麦的穗发芽抗性。测定小麦整穗发芽常 用的方法有沙培法、发芽纸发芽法、塑料袋保湿法、 模拟降雨法、纱布保湿法等 ${ }^{[11-12]}$ 。

小麦穗发芽是受多基因调控的数量性状, 存在 微效和主效基因 ${ }^{[13]}$ 。连锁分析与全基因组关联分析目 前已成为数量性状基因定位和挖掘的重要途径 ${ }^{[14]}$ 。许 多研究通过双单倍体(doubled haploid, DH)或重组自 交系(recombinant inbred lines, RIL)等人工作图群体,
将穗发芽相关基因定位于 $2 \mathrm{AL} 、 2 \mathrm{BS} 、 3 \mathrm{AS} 、 3 \mathrm{AL}$ 、

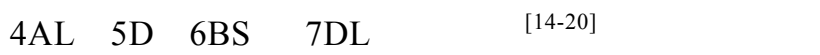
受限于遗传群体亲本间的差异度及标记密度等的不 同, QTL 定位的区间较大，仅能分析部分等位基因。 全基因组关联分析 (genome-wide association study, GWAS)与连锁分析互补, 可以高效定位和挖掘多个 小麦穗发芽相关的优异等位基因 ${ }^{[10]}$ 。Kulwal 等 ${ }^{[21]}$ 利用 1166 个简单序列重复(simple sequence repeat, SSR)和多样性芯片(diversity arrays technology, DArT) 分子标记, 对 208 份白皮冬小麦品种 4 年的穗发芽 率进行测定, 定位了 8 个与穗发芽相关的数量性状 基因座(quantitative trait locus, QTL)，分布在 1BS、 2DS、4AL、6DL、7BS 和 7DS 染色体上, 并证实了 $7 \mathrm{BS}$ 是新的 QTL 位点。Jaiswal 等 ${ }^{[22]}$ 通过对 242 份普 通小麦的穗发芽率进行鉴定, 并结合 250 个 SSR 标 记对穗发芽性状进行 QTL 分析, 发现了 30 个小麦穗 发芽抗性相关的主效位点, 其中仅有 8 个标记位点 与前人研究结果相同, 其余 22 个标记位点均处在前 人未报道的染色体区域。Lin 等 ${ }^{[23]}$ 首次使用 $9 \mathrm{~K}$ 和 $90 \mathrm{~K}$ 单核苷酸多态性(single nucleotide polymorphism, SNP)基因芯片对 155 份美国冬小麦品种(系)的穗发芽 率进行全基因组关联分析, 共检测到 12 个与穗发芽相 关的 QTL, 其中 $3 \mathrm{AS} 、 3 \mathrm{AL} 、 3 \mathrm{~B} 、 4 \mathrm{AL}$ 和 $7 \mathrm{~A}$ 是 QTL 分布频率较大的区域。Zhu 等 ${ }^{[24]}$ 利用 $90 \mathrm{~K}$ SNP 基因芯 片对 192 份小麦品种(系)的穗发芽率进行全基因组关联 分析, 检测到 23 个显著关联位点, 解释了 $6.0 \% \sim 18.9 \%$ 的表型变异, 其中 $1 \mathrm{~A} 、 3 \mathrm{~B}$ 和 $6 \mathrm{~B}$ 是抗性位点的热点区 域。Zuo 等 ${ }^{[25]}$ 对周 $8425 \mathrm{~B} \times$ 中国春重组自交系群体家系 和 166 份普通小麦的籽粒发芽率进行了 QTL 定位及 GWAS 分析, 研究结果除发现位于 $3 \mathrm{AS} 、 6 \mathrm{AL} 、 7 \mathrm{BL}$ 和 $3 \mathrm{DL}$ 上已报道的 QTL 外, 还挖掘了位于 $5 \mathrm{~A} 、 7 \mathrm{~A} 、 4 \mathrm{~B}$ 、 $3 \mathrm{D} 、 6 \mathrm{D}$ 染色体上的 8 个新位点。 
虽然前人在小麦穗发芽的鉴定、基因的篮选及 其定位等方面取得了一定进展，但由于小麦穗发芽 的遗传机制较为复杂，遗传背景来源不同的材料携 带着不同的抗性因子 ${ }^{[10]}$ 。因此, 为了进一步发掘穗 发芽相关基因并开发相关功能标记, 本研究对 207 份小麦品种(系)的整穗发芽率进行鉴定, 结合 SNP 标记进行全基因组关联分析, 以期为小麦穗发芽遗 传机制研究和分子育种提供参考。

\section{1 材料与方法}

\section{1 供试材料}

供试小麦品种(系)共计 207 份, 是我国各麦区主 推品种(系)、部分骨干亲本和历史品种。其中国内品 种(系) 165 份, 包含黄淮麦区 93 份, 西南麦区 12 份, 长江麦区 29 份, 北部麦区 31 份以及国外品种(系) 42 份，供试材料在不同区域间的分布频率依次为: $45 \% 、 6 \% 、 14 \% 、 15 \%$ 和 $20 \%$ ，上述供试材料均由中 国农业科学院作物科学研究所小麦品质课题组夏先 春研究员惠赠。供试材料分别于 2017-2018 (简称 E1)和 2018-2019 年度(简称 E2)种植于新疆农业科 学院玛纳斯试验站, 单行种植, 行长 $2 \mathrm{~m}$, 行距 25 $\mathrm{cm}$, 施肥、滴灌、防虫及除草同当地田间管理。以 连续 2 年的均值为平均环境(简称 E3)。

\section{2 整穗发芽的表型鉴定及分析}

2017-2018 和 2018-2019 年度的供试材料均 在室内进行表型鉴定。在小麦生长到蜡熟后期时, 剪取每份材料的 10 个主茎穗(带穗下节), 每 5 穗结 扎为一个重复, 室内风干 $1 \mathrm{~d}$, 立即存放于 $-20^{\circ} \mathrm{C}$ 的 冰箱内以维持其休眠性, 待收获全部材料后统一进 行穗发芽实验。先将整穗在蒸馏水中浸泡 10 12 h, 再 用 $0.1 \%$ 次氯酸钠溶液浸泡消毒 $15 \mathrm{~min}$ 后, 用无菌水冲 洗干净, 用发芽纸卷裹, 保鲜袋保湿, 置于人工气候培 养箱(温度 $20^{\circ} \mathrm{C}$, 光周期为 $16 \mathrm{~h}$ 昼 $/ 8 \mathrm{~h}$ 夜, 相对湿度为 $80 \%$ )培养 $7 \mathrm{~d}$ 后取出, 在电热恒温烘箱 $\left(150^{\circ} \mathrm{C}\right)$ 内快速烘 干, 阻止其继续发芽, 手工脱粒, 以种胚破裂为鉴定标 准 ${ }^{[26]}$, 记录每份材料的穗发芽率, 2 次重复的平均值为 此材料在该年度的穗发芽率。整穗发芽率(sprouting rate, $\mathrm{SR})=5$ 穗的发芽粒数/总粒数 $\times 100 \%$ 。

采用 Microsoft Excel 2016 进行基本数据统计与 分析, 采用 SPSS 21.0、QTL IciMapping V4.1 软件进 行描述性统计分析和方差分析 ${ }^{[27]}$ 。

\section{3 群体结构分析和主成分分析}

应用 Tassel 5.0 软件计算多态性信息量(PIC, polymorphic information content), PIC $=1-\Sigma P^{2}{ }_{i j}\left(P^{2}{ }_{i j}\right.$
表示第 $i$ 个位点的第 $j$ 个等位变异出现的频率 ${ }^{[28]}$ 。 从篮选过的标记中, 选取 2000 个最小等位基因频率 大于 $10 \%$ 且在染色体上均匀分布的 SNP 标记, 利用 Structure 2.3.4 软件进行群体结构分析。参数设置: Length of Burn-Period=10,000, MCMC Reps after Burn-in=100,000, 选择 Admixture Ancestry 模型和 Dependent Allele Frequencies 模式, 令 $K=2 \sim 12$, 每个 $K$ 值重复运行 5 次。将不同 $K$ 值下重复运行 5 次的 结果上传至 Structure Harvester (http://taylor0.biology.ucla.edu/struct harvest/ $)^{[29]}$, 使用 Tassel 5.0 软件 绘制群体结构分析图。

利用 TASSEL5.0 软件进行主成分分析(principle component analysis, PCA), 利用 ggplot2 工具绘制主 成分分析图。

\section{4 全基因组关联分析}

实验室前期使用 90K SNP 基因芯片对 207 份自 然群体材料进行了基因分型，共获得 16,686 个高质 量 SNP 标记。基于这些高质量 SNP 标记, 使用 Tassel 5.0 软件中的 MLM $(\mathrm{Q}+\mathrm{K})$ 模型对 207 份小麦品种(系) 在不同环境下的整穗发芽率进行全基因组关联分析, 以 $P=1.0 \times 10^{-3}$ 为阈值, 判定 SNP 标记与目标性状关 联的显著性 ${ }^{[30]}$ 。

\section{5 连锁不平衡分析}

以位点间的相关系数平方 $\left(r^{2}\right)$ 作为衡量多态性 位点两两之间的连锁不平衡(linkage disequilibrium, LD)参数。采用 Tassel 5.0 软件计算 $r^{2}$, 以第 95 百分 位的 $r^{2}$ 值作为阈值估测 LD 衰减距离。考虑连锁群 (linkage group)间连锁不平衡背景的影响, 对连锁群 间的 $r^{2}$ 值进行平方根转换, 以大于此分布 $95 \%$ 的参 数值为阈值, 用来截取同一连锁群内 $\mathrm{LD}$ 的衰减距

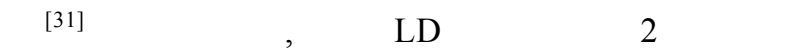
认为是 2 个不同的位点。

\section{2 结果与分析}

\section{1 小麦穗发芽的表型分析}

本研究采用整穗发芽法对 207 份供试材料进行 表型鉴定(图 1 和图 2), 研究结果表明, 在 2 个环境 下, 整穗发芽率的变异幅度分别为 $12.98 \%$ 100.00\% 和 $13.84 \% \sim 100.00 \%$, 变异系数为 0.34 和 0.25 , 平均 值均较高, 分别为 $74.31 \%$ 和 $84.80 \%$, 表明遗传背景 来源不同的材料在 2 个环境下均表现出丰富的表型 变异, 但自然群体内多数材料的穗发芽抗性较弱, 具有较大的遗传改良潜力。不同年份间相关系数为 


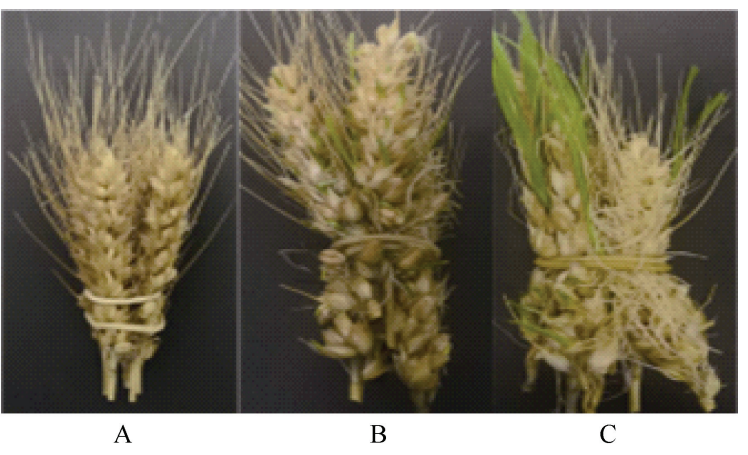

图 1 部分供试材料的整穗发芽图

Fig. 1 Pre-harvest sprouting diagram of some tested materials A: 京冬 8 号; B: 淮麦 20 号; C: 郑麦 2 号。

A: Jingdong 8; B: Huaimai 20; C: Zhengmai 2.

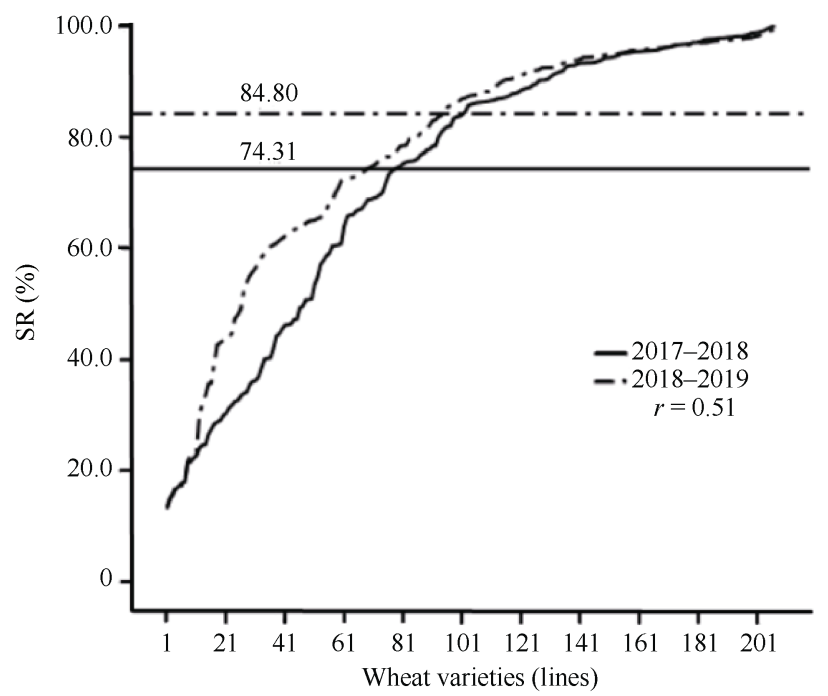

图 2207 份材料在 2 个环境下的整穗发芽率变异

Fig. 2 Variation of germination rate of intact spike in 207 wheat genotypes detected in two environments SR: 整穗发芽率。SR: sprouting rate.

0.51 。方差分析(表 1)显示, 2 个环境下测得供试材料 间整穗发芽率差异极显著 $(P=0.00001)$ ，基因型、环 境及基因型与环境互作皆影响小麦穗发芽的抗性。

其遗传力为 0.60 , 表明小麦穗发芽抗性主要由基因 型决定, 但也受到环境因素的影响, 遗传因素是导 致其表型变异的主要原因。

\section{$2.2 \mathrm{SNP}$ 多态性及分布}

使用 90K SNP 基因芯片对 E1、E2 及平均环境 (E3)下的 207 份小麦品种(系)的整穗发芽率进行检测, 经过优质篮选, 最终采用 16,686 个具有多态性的 SNP 标记进行 GWAS 分析, 平均单条染色体包含 795 个 SNP 标记, 其中分布在 A、B 和 D 基因组染 色体上的 SNP 标记数分别为 7145、7343 和 2198。

A、B 基因组的染色体组所用标记数目、标记密度和 多态性信息含量均高于 D 染色体组。物理图谱总长 度为 $14,043.30 \mathrm{Mb}$, 每个标记间的平均物理距离为 $1.27 \mathrm{Mb}, \mathrm{SNP}$ 标记的 PIC 值介于 0.01 0.38 之间(表 2)。

\section{3 群体结构及连锁不平衡分析}

利用 Structure 2.3.4 软件对 207 份供试材料进行 群体结构分析(图 3-A, B)。结果显示, 当 $K=3$ 时, $\Delta \mathrm{K}$ 达到峰值, 曲线变化程度最大。PCA 分析(图 3-C)与 Structure 分析结果一致。供试材料可分为 3 个亚群, 其中, 亚群 1 有 60 份品种(系), 主要来自法国(14 份) 和中国北京(13 份); 亚群 2 有 62 份品种(系), 主要来 自中国河南(27 份); 亚群 3 有 85 份品种(系), 主要来 自中国河南(17 份)、陕西(16 份)和江苏(13 份)。3个 亚群所含材料的分布频率依次为: $28.99 \%$ 、29.95\% 和 41.06\%。经计算得到 207 份小麦品种(系)在基因 组 $A 、 B 、 D$ 和全基因组的 $L D$ 衰减距离分别为 $5 、 3 、$ 1 和 $3 \mathrm{Mb}$, 依据全基因组的 $\mathrm{LD}$ 衰减距离, 将在物理 图谱上前后 $3 \mathrm{Mb}$ 区间内的位点认定为一个候选位点。

\section{4 全基因组关联分析}

利用 TASSEL5.0 软件将 207 份小麦品种(系)的 整穗发芽率结合 90K SNP 芯片䇻选分型出的 16,686 个高质量 SNP 标记进行全基因组关联分析。基于 $\operatorname{MLM}(\mathrm{Q}+\mathrm{K})$ 模型, 当 $P \leq 0.001$ 时, 认为该标记与性 状显著关联, 在多个环境下检测到的位点视为可稳 定遗传的位点(图 4)。GWAS 分析结果表明, 共检测 到 34 个显著性位点, 分布于小麦 $3 \mathrm{~A} 、 3 \mathrm{~B} 、 4 \mathrm{~A} 、 4 \mathrm{~B}$ 、 $5 \mathrm{D} 、 6 \mathrm{~A} 、 6 \mathrm{~B} 、 6 \mathrm{D} 、 7 \mathrm{~B}$ 和 $7 \mathrm{D}$ 染色体上, 单个位点可 解释 $5.55 \%$ 11.63\%的表型变异。其中，定位于 $6 \mathrm{~B}$

表 1207 份自然群体小麦穗发芽方差分析

Table 1 ANOVA of sprouting in 207 genotypes used in this study

\begin{tabular}{|c|c|c|c|c|c|c|}
\hline $\begin{array}{c}\text { 变异来源 } \\
\text { Source of variance }\end{array}$ & $\begin{array}{c}\text { 自由度 } \\
\text { DF }\end{array}$ & $\begin{array}{c}\text { 平方和 } \\
\mathrm{SS}\end{array}$ & $\begin{array}{c}\text { 均方 } \\
\text { MS }\end{array}$ & $\begin{array}{c}F \text { 值 } \\
F \text {-value }\end{array}$ & $\begin{array}{c}P \text { 值 } \\
P \text {-value }\end{array}$ & $\begin{array}{c}\text { 遗传力 } \\
h^{2}\end{array}$ \\
\hline 基因型 Genotype (G) & 206 & $95,102,272.00$ & $312,836.40$ & 540.38 & 0.00001 & \\
\hline 环境 Environment (E) & 1 & $756,525,632.00$ & $378,262,816.00$ & $653,396.18$ & 0.00001 & \\
\hline 基因型×环境 $\mathrm{G} \times \mathrm{E}$ & 443 & $94,041,216.00$ & $212,282.65$ & 366.68 & 0.00001 & 0.60 \\
\hline 误差 Error & 747 & $432,451.71$ & 578.91 & & & \\
\hline 总变异 Total & 1397 & $946,109,312.00$ & & & & \\
\hline
\end{tabular}


表 2 标记的分布及多态性

Table 2 Genome coverage and polymorphism of markers

\begin{tabular}{|c|c|c|c|c|c|}
\hline \multirow{2}{*}{$\begin{array}{c}\text { 染色体 } \\
\text { Chromosome }\end{array}$} & \multirow{2}{*}{$\begin{array}{c}\text { 标记数目 } \\
\text { No. of markers }\end{array}$} & \multirow{2}{*}{$\begin{array}{c}\text { 染色体长度 } \\
\text { Chromosome length }(\mathrm{Mb})\end{array}$} & \multirow{2}{*}{$\begin{array}{c}\text { 标记密度 } \\
\text { Density of marker }\end{array}$} & \multicolumn{2}{|c|}{ 多态信息量 PIC } \\
\hline & & & & 平均值 Mean & 变异范围 Range \\
\hline $1 \mathrm{~A}$ & 1263 & 592.38 & 0.47 & 0.27 & $0.01-0.38$ \\
\hline $2 \mathrm{~A}$ & 1145 & 780.46 & 0.68 & 0.24 & $0.01-0.38$ \\
\hline $3 \mathrm{~A}$ & 891 & 749.46 & 0.84 & 0.25 & $0.01-0.38$ \\
\hline $4 \mathrm{~A}$ & 708 & 741.73 & 1.05 & 0.25 & $0.01-0.38$ \\
\hline $5 \mathrm{~A}$ & 960 & 709.43 & 0.74 & 0.28 & $0.01-0.38$ \\
\hline $6 \mathrm{~A}$ & 1006 & 617.40 & 0.61 & 0.27 & $0.03-0.38$ \\
\hline $7 \mathrm{~A}$ & 1172 & 736.44 & 0.63 & 0.25 & $0.01-0.38$ \\
\hline $1 \mathrm{~B}$ & 1292 & 688.60 & 0.53 & 0.27 & $0.01-0.38$ \\
\hline $2 \mathrm{~B}$ & 1291 & 799.62 & 0.62 & 0.26 & $0.01-0.38$ \\
\hline $3 \mathrm{~B}$ & 1087 & 829.32 & 0.76 & 0.27 & $0.01-0.38$ \\
\hline 4B & 571 & 672.56 & 1.18 & 0.26 & $0.01-0.38$ \\
\hline $5 \mathrm{~B}$ & 1156 & 712.82 & 0.62 & 0.28 & $0.01-0.38$ \\
\hline $6 \mathrm{~B}$ & 1085 & 720.82 & 0.66 & 0.25 & $0.01-0.38$ \\
\hline $7 \mathrm{~B}$ & 861 & 750.49 & 0.87 & 0.26 & $0.02-0.38$ \\
\hline $1 \mathrm{D}$ & 568 & 495.14 & 0.87 & 0.13 & $0.01-0.38$ \\
\hline $2 \mathrm{D}$ & 482 & 650.94 & 1.35 & 0.25 & $0.02-0.38$ \\
\hline $3 \mathrm{D}$ & 232 & 613.92 & 2.65 & 0.24 & $0.01-0.38$ \\
\hline $4 \mathrm{D}$ & 99 & 508.58 & 5.14 & 0.25 & $0.08-0.38$ \\
\hline $5 \mathrm{D}$ & 240 & 563.41 & 2.35 & 0.26 & $0.02-0.38$ \\
\hline $6 \mathrm{D}$ & 319 & 472.61 & 1.48 & 0.25 & $0.03-0.38$ \\
\hline $7 \mathrm{D}$ & 260 & 637.17 & 2.45 & 0.23 & $0.01-0.38$ \\
\hline A 染色体组 Total genome A & 7145 & 4927.30 & 0.72 & 0.26 & $0.01-0.38$ \\
\hline B 染色体组 Total genome B & 7343 & 5174.23 & 0.75 & 0.27 & $0.01-0.38$ \\
\hline D 染色体组 Total genome D & 2198 & 3941.77 & 2.33 & 0.23 & $0.01-0.38$ \\
\hline 总计 Total & 16686 & 14043.30 & 1.27 & 0.25 & $0.01-0.38$ \\
\hline
\end{tabular}

染色体上的标记 wsnp Ex c14101 22012676 在 E1、 $\mathrm{E} 2$ 及平均环境下被共同检测到, 对表型的贡献率为 $5.86 \% \sim 11.61 \%$; 另有 15 个标记位点均在 1 个环境及 平均环境下被检测到，分布于 $3 \mathrm{~A} 、 6 \mathrm{~A} 、 6 \mathrm{~B}$ 及 $7 \mathrm{~B}$ 染 色体上，其贡献率为 $5.55 \%$ 11.63\%，这 16 个可重复 检测到的位点属稳定遗传位点, 其中 $6 \mathrm{~B}$ 染色体是携 带小麦穗发芽相关基因的热点区域; 其余的 18 个标 记位点均仅在 1 个环境或平均环境下被检测到。表 明在影响小麦穗发芽的众多基因中，存在效应稳定 的 QTL，同时也受到基因型与环境互作的影响，方差 分析的结果也证实了这一点。将 GWAS 检测到的 34 个 显著性位点与前人的定位结果进行比较, 发现 10 个位 点被定位到前人报道的基因/标记/QTL 区间附近，其余 24 个标记位点均处在前人未报道的染色体区域(表 3)。
2.5 小麦穗发芽候选基因功能预测

将表型效应值大且能稳定遗传的 SNP 标记在普 通小麦中国春基因组数据库中进行检索, 并在 NCBI 数据库中进行 BLASTx 序列比对, 共挖掘了 13 个最有可能与穗发芽相关的候选基因(表 4)。穗发 芽候选基因主要与种子的休眠、植物激素的生物合 成及信号转导相关。其中, 定位于 $3 \mathrm{~A} 、 6 \mathrm{~B} 、 6 \mathrm{D}$ 和 7B 染色体上的基因 TraesCS3A01G589400LC、 TraesCS6B01G138600/TraesCS6B01G516700LC/ TraesCS6B01G548900LC、TraesCS6D01G103600 及 TraesCS7B01G200100均编码锌指结构蛋白; 定位于 3B、6A 和 $6 \mathrm{~B}$ 染色体上的基因 TraesCS3B01G415 900LC、TraesCS6A01G144700LC 及 TraesCS6B01G2 94800 均编码 F-box 家族蛋白; 定位于 6B 染色体上 

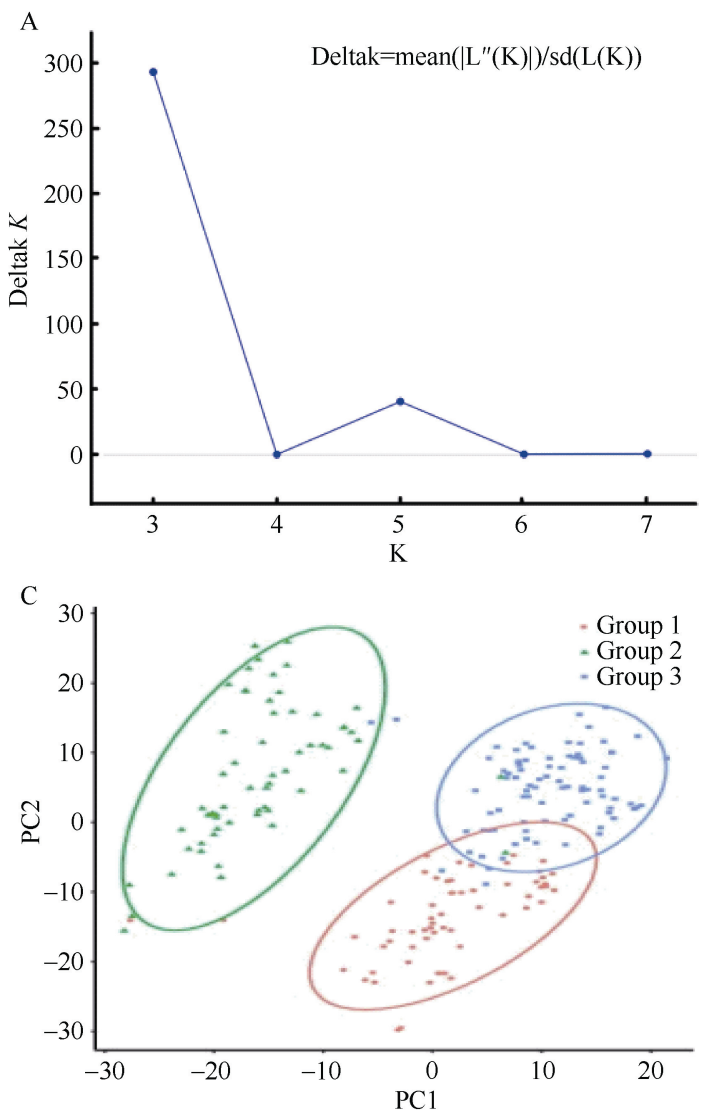

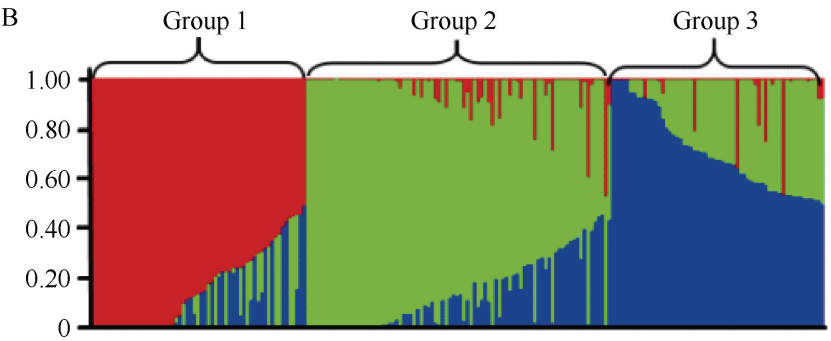

图 3207 份小麦品种(系)群体结构分析

Fig. 3 Population structure analysis of 207 wheat varieties (lines)
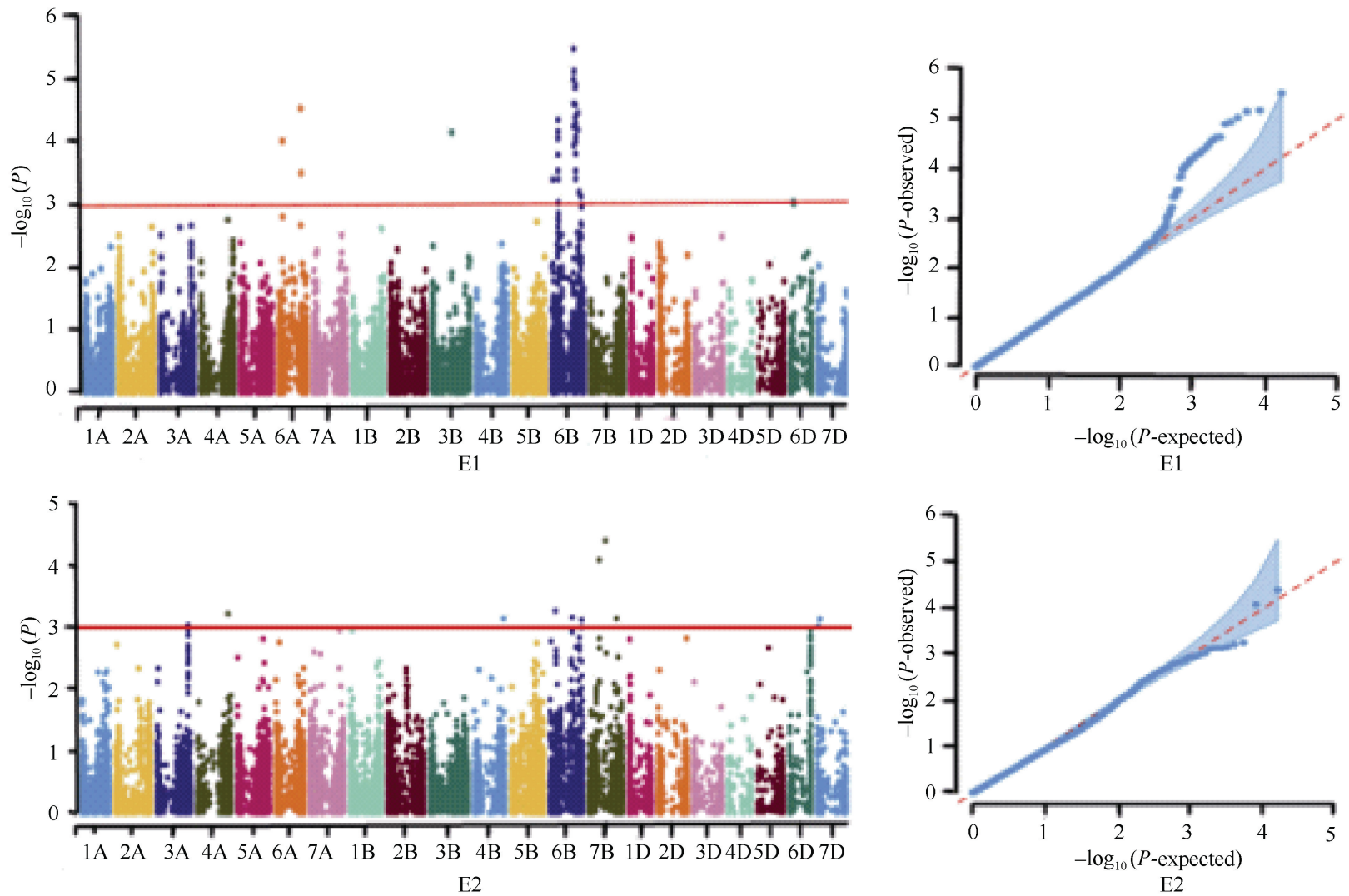

(图 4) 

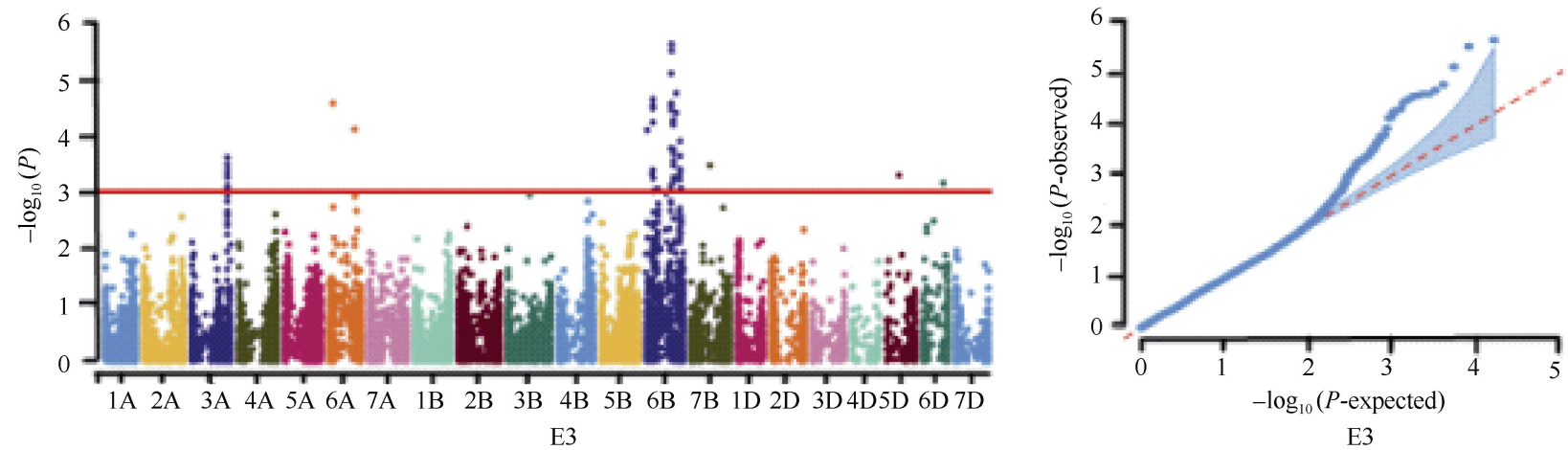

图 4 不同环境中穗发芽的曼哈顿图和 Q-Q 图

Fig. 4 Manhattan and Q-Q diagrams of pre-harvest sprouting traits in different environments

E1: 2017-2018 年, 玛纳斯; E2: 2018-2019 年, 玛纳斯; E3: 平均环境。

E1: 2017 and 2018 in Manasi; E2: 2018 and 2019 in Manasi; E3: average environment.

表 3 小麦穗发芽显著关联位点信息

Table 3 Information of significant association sites for PHS

\begin{tabular}{|c|c|c|c|c|c|c|}
\hline \multirow{2}{*}{$\begin{array}{c}\text { 标记 } \\
\text { Marker }\end{array}$} & \multirow{2}{*}{$\begin{array}{c}\text { 染色体 } \\
\text { Chr. }\end{array}$} & \multirow{2}{*}{$\begin{array}{c}\text { 位置 } \\
\text { Position (Mb) }\end{array}$} & \multicolumn{2}{|c|}{ MLM } & \multirow{2}{*}{$\begin{array}{c}\text { 环境 } \\
\text { Environment }\end{array}$} & \multirow{2}{*}{$\begin{array}{c}\text { 已报道的 QTL/标记/ } \\
\text { 基因 Known } \\
\text { QTL/marker/gene }\end{array}$} \\
\hline & & & $\begin{array}{c}P \text { 值 } \\
P \text {-value }\end{array}$ & $\begin{array}{l}\text { 贡献率 } \\
R^{2}(\%)\end{array}$ & & \\
\hline Kukri_c8465_54 & $3 \mathrm{~A}$ & $684.04-685.36$ & $2.35 \mathrm{E}-04-9.14 \mathrm{E}-04$ & $5.55-8.75$ & $\mathrm{E} 2 / \mathrm{E} 3$ & TaVp-1 $1^{[32]}$ \\
\hline Kukri_c9259_421 & $4 \mathrm{~A}$ & 673.07 & $5.95 \mathrm{E}-04$ & 6.34 & E2 & $I W B 23723^{[23]}$ \\
\hline RAC875_rep_c107892_142 & $6 \mathrm{~A}$ & 77.78 & $2.56 \mathrm{E}-05-9.28 \mathrm{E}-05$ & $8.04-9.25$ & $\mathrm{E} 1 / \mathrm{E} 3$ & \\
\hline Kukri_c5744_92 & $6 \mathrm{~A}$ & 483.90 & $2.78 \mathrm{E}-05-7.41 \mathrm{E}-04$ & $8.34-9.25$ & E1/E3 & \\
\hline RAC875_c43536_193 & $6 \mathrm{~A}$ & 490.50 & $3.03 \mathrm{E}-04$ & 6.94 & E1 & \\
\hline IAAV8536 & $3 \mathrm{~B}$ & 422.52 & $6.78 \mathrm{E}-05$ & 9.81 & E1 & $\operatorname{TaDFR}^{[33]}$ \\
\hline Tdurum_contig60051_838 & $4 \mathrm{~B}$ & 644.68 & $7.10 \mathrm{E}-04$ & 9.42 & E2 & $X w m c 349^{[34]}$ \\
\hline CAP11_c2542_147 & $6 \mathrm{~B}$ & 24.92 & $7.71 \mathrm{E}-05-3.83 \mathrm{E}-04$ & $6.71-8.29$ & $\mathrm{E} 1 / \mathrm{E} 3$ & TaCYP707A1 $1^{[35]}$ \\
\hline Kukri_c33668_877 & $6 \mathrm{~B}$ & 119.53 & $4.55 \mathrm{E}-04-5.32 \mathrm{E}-04$ & $6.05-6.16$ & $\mathrm{E} 2 / \mathrm{E} 3$ & $A X-108844376^{[24]}$ \\
\hline GENE-3171_203 & $6 \mathrm{~B}$ & $135.11-138.65$ & $2.15 \mathrm{E}-05-5.50 \mathrm{E}-04$ & $6.09-9.71$ & E1/E3 & \\
\hline BS00069412_51 & $6 \mathrm{~B}$ & 143.20 & $9.03 \mathrm{E}-04$ & 5.64 & E1 & \\
\hline Excalibur_c18382_760 & $6 \mathrm{~B}$ & 151.13 & $9.24 \mathrm{E}-04$ & 5.60 & E3 & \\
\hline wsnp_Ku_c2614_4970880 & $6 \mathrm{~B}$ & 226.87 & $8.44 \mathrm{E}-04$ & 5.59 & E3 & \\
\hline Tdurum_contig13698_141 & $6 \mathrm{~B}$ & 475.73 & $7.54 \mathrm{E}-04$ & 5.70 & E3 & \\
\hline RFL_Contig6050_941 & $6 \mathrm{~B}$ & $481.47-481.86$ & $3.10 \mathrm{E}-06-1.63 \mathrm{E}-04$ & $8.83-11.63$ & $\mathrm{E} 1 / \mathrm{E} 3$ & \\
\hline wsnp_Ex_c3640_6644345 & $6 \mathrm{~B}$ & 485.54 & $2.36 \mathrm{E}-05-1.08 \mathrm{E}-04$ & $8.21-11.04$ & E1/E3 & $I W B 2831^{[24]}$ \\
\hline wsnp_Ex_c14101_22012676 & $6 \mathrm{~B}$ & 492.02 & $2.26 \mathrm{E}-06-6.77 \mathrm{E}-04$ & $5.86-11.61$ & $\mathrm{E} 1 / \mathrm{E} 2 / \mathrm{E} 3$ & \\
\hline wsnp_Ex_c6143_10747643 & $6 \mathrm{~B}$ & $516.08-519.15$ & $1.30 \mathrm{E}-05-1.65 \mathrm{E}-04$ & $8.30-10.65$ & E1/E3 & \\
\hline Kukri_c16568_287 & $6 \mathrm{~B}$ & 522.49 & $4.81 \mathrm{E}-05-1.69 \mathrm{E}-04$ & $7.21-8.45$ & $\mathrm{E} 1 / \mathrm{E} 3$ & \\
\hline Excalibur_c7785_123 & $6 \mathrm{~B}$ & $526.48-528.92$ & $1.19 \mathrm{E}-056.21 \mathrm{E}-04$ & $5.94-10.02$ & E1/E3 & \\
\hline Excalibur_c11245_880 & $6 \mathrm{~B}$ & 530.57 & $2.79 \mathrm{E}-04-5.34 \mathrm{E}-04$ & $6.06-6.83$ & $\mathrm{E} 1 / \mathrm{E} 3$ & \\
\hline wsnp_Ex_c3990_7223090 & $6 \mathrm{~B}$ & 577.48 & $1.67 \mathrm{E}-05-6.19 \mathrm{E}-05$ & $8.45-9.95$ & E1/E3 & Qphs.ahau-6B $B^{[36]}$ \\
\hline RAC875_c57261_265 & $6 \mathrm{~B}$ & 609.38 & $6.10 \mathrm{E}-04-6.34 \mathrm{E}-04$ & $5.99-6.02$ & E1 & \\
\hline
\end{tabular}


(续表 3)

\begin{tabular}{|c|c|c|c|c|c|c|}
\hline \multirow{2}{*}{$\begin{array}{c}\text { 标记 } \\
\text { Marker }\end{array}$} & \multirow{2}{*}{$\begin{array}{c}\text { 染色体 } \\
\text { Chr. }\end{array}$} & \multirow{2}{*}{$\begin{array}{c}\text { 位置 } \\
\text { Position }(\mathrm{Mb})\end{array}$} & \multicolumn{2}{|c|}{ MLM } & \multirow{2}{*}{$\begin{array}{c}\text { 环境 } \\
\text { Environment }\end{array}$} & \multirow{2}{*}{$\begin{array}{c}\text { 已报道的 QTL/标记/ } \\
\text { 基因 Known } \\
\text { QTL/marker/gene }\end{array}$} \\
\hline & & & $\begin{array}{c}P \text { 值 } \\
P \text {-value }\end{array}$ & $\begin{array}{l}\text { 贡献率 } \\
R^{2}(\%)\end{array}$ & & \\
\hline RAC875_rep_c117796_352 & $6 \mathrm{~B}$ & 632.97 & $5.23 \mathrm{E}-04-5.35 \mathrm{E}-04$ & $6.19-6.21$ & E3 & \\
\hline wsnp_CV776265A_Ta_2_1 & $6 \mathrm{~B}$ & $651.01-652.00$ & $1.21 \mathrm{E}-04-7.21 \mathrm{E}-04$ & $5.78-7.51$ & E1/E3 & \\
\hline BS00023032_51 & $6 \mathrm{~B}$ & 664.38 & $8.28 \mathrm{E}-04$ & 5.90 & E3 & \\
\hline IAE36519 & $6 \mathrm{~B}$ & $701.98-704.04$ & 7.44E-04-9.92E-04 & $5.87-6.09$ & E2 & \\
\hline wsnp_Ku_c18780_28136150 & $7 \mathrm{~B}$ & 223.61 & $8.12 \mathrm{E}-05$ & 10.12 & E2 & \\
\hline Excalibur_c25719_238 & 7B & 363.24 & $3.92 \mathrm{E}-05-3.24 \mathrm{E}-04$ & $6.64-8.89$ & $\mathrm{E} 2 / \mathrm{E} 3$ & \\
\hline RAC875_c4834_694 & $7 \mathrm{~B}$ & 613.38 & $7.14 \mathrm{E}-04$ & 5.87 & E2 & Dorm- $1^{[37]}$ \\
\hline BobWhite_c8092_726 & $5 \mathrm{D}$ & 246.30 & 4.94E-04 & 6.22 & E3 & \\
\hline wsnp_Ex_c1249_2399894 & $6 \mathrm{D}$ & $67.39-68.10$ & 8.81E-04-9.23E-04 & $5.72-5.78$ & E1 & \\
\hline D_wsnpbe403818_Contig1_1 & $6 \mathrm{D}$ & 389.70 & $6.71 \mathrm{E}-04$ & 5.79 & E3 & \\
\hline D_contig10382_335 & $7 \mathrm{D}$ & $23.50-55.42$ & $7.24 \mathrm{E}-04-9.41 \mathrm{E}-04$ & $5.70-6.15$ & E2 & $\operatorname{MST101} 1^{[37]}$ \\
\hline
\end{tabular}

E1: 2017-2018 玛纳斯; E2: 2018-2019 玛纳斯; E3: 平均环境。

E1: in 2017 and 2018 in Manasi; E2: in 2018 and 2019 in Manasi; E3: average environment.

表 4 候选基因信息

Table 4 Information of candidate genes

\begin{tabular}{lccll}
\hline \multicolumn{1}{c}{$\begin{array}{c}\text { 位点 } \\
\text { Marker }\end{array}$} & $\begin{array}{c}\text { 染色体 } \\
\text { Chr. }\end{array}$ & $\begin{array}{c}\text { 物理位置 } \\
\text { Position (Mb) }\end{array}$ & \multicolumn{1}{c}{$\begin{array}{c}\text { 基因 } \\
\text { Gene }\end{array}$} & \multicolumn{1}{c}{$\begin{array}{c}\text { 基因注释或编码蛋白 } \\
\text { Gene annotation or coding protein }\end{array}$} \\
\hline Kukri_c8465_54 & 3A & 684.76 & TraesCS3A01G589400LC & Zinc finger MYM-type-like protein \\
IAAV8536 & 3B & 421.53 & TraesCS3B01G415900LC & F-box protein \\
RAC875_rep_c107892_142 & 6A & 77.61 & TraesCS6A01G144700LC & F-box family protein \\
& 6A & 77.54 & TraesCS6A01G108800 & Myb-like transcription factor family protein \\
GENE-3171_203 & 6B & 135.71 & TraesCS6B01G138200 & Myb family transcription factor-like \\
& 6B & 135.94 & TraesCS6B01G138600 & RING/U-box superfamily protein \\
RFL_Contig6050_941 & 6B & 481.79 & TraesCS6B01G511400LC & Anaerobic nitric oxide reductase transcription regulator NorR \\
wsnp_Ex_c14101_22012676 & 6B & 491.55 & TraesCS6B01G516700LC & Zinc finger (C3HC4-type RING finger) family protein \\
Excalibur_c7785_123 & 6B & 528.92 & TraesCS6B01G294800 & F-box protein \\
& 6B & 527.93 & TraesCS6B01G293700 & Myb family transcription factor-like \\
& 6B & 526.49 & TraesCS6B01G548900LC & Zinc finger MYM-type-like protein \\
Excalibur_c25719_238 & 7B & 363.00 & TraesCS7B01G200100 & Zinc finger C-x8-C-x5-C-x3-H type family protein \\
wsnp_Ex_c1249_2399894 & 6D & 67.39 & TraesCS6D01G103600 & Zinc finger BED domain-containing protein \\
& & & & DAYSLEEPER \\
\hline
\end{tabular}

的基因 TraesCS6B01G511400LC 功能注释为厌氧型

\section{一氧化氮还原酶转录调控因子。}

\section{3 讨论}

\section{1 小麦穗发芽性状的分析}

小麦穗发芽的抗性机制较为复杂, 主要受籽 粒休眠性、穗部形态、种皮颜色及环境等因素的 影响 ${ }^{[38-39]}$ 。朱冬梅等 ${ }^{[40]}$ 对 33 份长江中下游麦区主
推品种的穗发芽抗性进行评价, 结果表明, 品种的 休眠特性与其穗发芽抗性呈正相关。苗西磊等 ${ }^{[41]}$ 利 用相关的分子标记并结合整穗发芽实验，证实穗部 形态如麦芒、颖壳及其抑制物对小麦穗发芽具有抑 制作用。Warner 等 ${ }^{[42]}$ 的研究指出, 种皮颜色与小麦 穗发芽抗性呈正相关。在众多的环境因素中, 温度 和水分是影响穗发芽的主要因素。温度在 $26^{\circ} \mathrm{C}$ 以上 时, 籽粒的休眠程度会降低或丧失; 在 $15^{\circ} \mathrm{C}$ 以下时, 
籽粒的休眠程度加深 ${ }^{[43-44]} ; 20^{\circ} \mathrm{C}$ 时，小麦的发芽率 最高, 温度继续升高, 发芽率降低 ${ }^{[45]}$ 。从穗发芽的定 义可以看出, 水分是导致小麦穗发芽的直接外界因 素。本研究利用整穗发芽法在人工气候培养箱(温度 $20^{\circ} \mathrm{C}$, 相对湿度为 $80 \%$ )进行发芽实验, 不仅能反映 出各品种(系)间穗发芽受种子本身的休眠特性及穗 部形态等的影响, 还能体现出环境等因素对其抗性 的作用, 能较好的反映出各小麦品种(系)间的综合 抗性。研究结果显示, 在同一年份及不同年份间, 整 穗发芽率的变异幅度较大 $(12.98 \%$ 100.00\% 和 $13.84 \% \sim 100.00 \%)$, 且平均值均高于标准差, 表明不 同小麦品种(系)可能有着不同的抗性因子, 抗性材 料间的抗性因子也不同, 因而表现出了丰富的表型 变异。与 2018 年相比, 207 份小麦品种(系)在 2019 年整穗发芽率的变异范围较小, 平均值较大, 究其 原因可能是受小麦成熟期间的温度及收获前降雨的 影响, 导致供试品种(系)整体的穗发芽抗性水平下 降。此外, 本研究在 2 个环境下的方差分析与朱玉 磊等 ${ }^{[13]}$ 利用 264 份供试材料在 3 个环境下分析整穗 发芽率的结果一致, 表明小麦穗发芽抗性既受基因 型调控, 也易受环境因素的影响, 同时基因与环境 互作效应对其影响显著，这也是导致不同年份间的 相关系数较低的原因。

\section{2 小麦穗发芽关联分析}

随着分子生物学及生物信息学的迅速发展, GWAS 分析与 QTL 定位已成为研究植物数量性状的 重要途径，小麦穗发芽相关基因的挖掘也得到了较大 程度的推动。Munkvold 等 ${ }^{[14]}$ 、Osa 等 ${ }^{[15]}$ 、Lin 等 ${ }^{[17]}$ 利 用不同的 RIL 群体结合基因芯片对小麦穗发芽进行 连锁分析, 定位了 $2 \mathrm{AL} 、 2 \mathrm{BS} 、 3 \mathrm{AS} 、 3 \mathrm{AL} 、 4 \mathrm{AL}$ 、 $5 \mathrm{D} 、 6 \mathrm{~B}$ 及 $7 \mathrm{D}$ 上的主效 QTL 位点，其中 $3 \mathrm{~A} 、 5 \mathrm{D}$ 、 6B 及 7D 位点与本研究相同, 验证了这些位点的重 要性, 同时也进一步证明了关联分析与连锁分析均 能检测到与目标性状显著相关的 QTL 位点。将 GWAS 检测结果与前人定位的结果相比较, 发现一 些已报道的基因/标记位点/QTL 在本研究中被重复 定位到, 如本研究定位于 $3 \mathrm{~A}$ 染色体上的显著性位 点 Kukri_c8465_54, 根据染色体上位置的比对结果 发现，该位点与 Bailey 等 ${ }^{[46]}$ 报道的调控种胚休眠性 的 TaVp-1 基因距离较近。定位于 4B 染色体上的标 记位点 Tdurum_contig60051_838 (644.68 Mb) 与 Rasul 等 ${ }^{[34]}$ 定位在 4B 染色体上的标记位点 Xwmc 349 $(640.9 \mathrm{Mb})$ 相距约 $4 \mathrm{Mb}$, 可能为同一位点。Zhu 等 ${ }^{[24]}$
定位了 3 个与穗发芽抗性相关的 QTL，且 6B 位点是 携带穗发芽抗性基因的热点区域, 这一结果与本研 究一致。同时, 本研究发现定位在 $6 \mathrm{~B}$ 染色体上的标 记 wsnp_Ex_c3990_7223090 (577.48 Mb)与 Z $\mathrm{hu}$ 等 ${ }^{[24]}$ 定位的 Qphs.ahau-6B (574.6 576.8 Mb)物理位置相 近, 可以推测这一区段内可能存在与穗发芽抗性相 关的基因。但本研究鉴定结果中有 24 个显著性位点 与相同染色体上已报道的位点在物理位置上相距较 远，如 7B 染色体上的 wsnp_Ku_c18780_28136150 $(223.61 \mathrm{Mb})$ 与王焕雪等 ${ }^{[47]}$ 定位在 $7 \mathrm{~B}$ 染色体上的 $A X-109349257(718.5 \sim 720.0 \mathrm{Mb})$ 相距约 $500 \mathrm{Mb}$ 。这 些小麦穗发芽相关位点可能均为新位点。

此外, 本研究检测到在 E1、E2 及平均环境下被 共同检测到, 物理位置为 $492.02 \mathrm{Mb}$, 对表型解释效 应为 $5.86 \% \sim 11.61 \%$ 。该位点可能是与小麦穗发芽抗 性相关的重要位点。对其进行候选基因的挖掘, 篮 选到的候选基因 TraesCS6B01G516700LC, 其基因 功能注释为锌指 ( $\mathrm{C} 3 \mathrm{HC} 4$ 型指环)家族蛋白, 该蛋白 的功能是通过调控植物内源激素-脱落酸 (abscisic acid, ABA)的灵敏性进而影响种子的休眠。今后将着 手开发多种标记(EST、EST-SSR、CAPS 等)用于加 密标记图谱, 同时构建适当的作图群体, 以准确定 位这些关联位点, 并对效应值大且稳定遗传的候选基 因进行图位克隆、功能验证等, 以期进一步剖析小麦穗 发芽的遗传机制。

\section{3 候选基因的功能分析}

本研究利用 GWAS 检测到 34 个与小麦穗发芽 显著关联的 SNP 标记位点, 并在普通小麦中国春基 因组数据库篮选获得 13 个可能与穗发芽相关的候 选基因。位于 $3 \mathrm{~A} 、 6 \mathrm{~B} 、 6 \mathrm{D}$ 和 7B 上的基因 TraesCS3 蛋白, 该蛋白的功能是通过调控植物内源激素-脱落 酸(abscisic acid, ABA)的灵敏性对种子的休眠进行 调控 ${ }^{[48]}$; 位于 $3 \mathrm{~B} 、 6 \mathrm{~A}$ 和 $6 \mathrm{~B}$ 上的基因 Traes CS3B01 G415900LC、TraesCS6A01G144700LC 及 TraesCS6B $01 G 294800$ 编码 F-box 家族蛋白, 该家族蛋白在植 物激素的信号转导, 光信号转导以及花器官发育等 生理过程有重要作用 ${ }^{[49]}$; 6B 染色体上的基因 TraesCS6B01G511400LC 注释为厌氧型一氧化氮还 原酶转录调控因子, 一氧化氮对植物种子的休眠解 除和萌发有促进作用 ${ }^{[50]}$; 位于 $6 \mathrm{~A}$ 和 $6 \mathrm{~B}$ 染色体上 的基因 TraesCS6A01G108800、TraesCS6B01G13 8200/TraesCS6B01G293700 编码 Myb 转录因子家族 蛋白, 该蛋白调控种子中类黄酮的生物合成, 对籽 
粒颜色有重要影响 ${ }^{[48]}$ 。Himi 等 ${ }^{[51]}$ 证明 $R$ 基因能够 促进类黄酮基因的转录，但在小麦白皮品种中并不 表达，红皮小麦因受控制种皮颜色的三重 $R$ 基因的 调控导致其穗发芽抗性较强, $R$ 基因与休眠位点紧 密连锁，在对应区间检测到 Myb 家族转录因子，并成 功开发相关标记。这对本研究在 $6 \mathrm{~A}$ 和 $6 \mathrm{~B}$ 染色上检测 到 Myb 转录因子区段具有借鉴作用, 但能否据此开发 有效的功能标记, 是我们下一步工作的重点。

\section{4 结论}

本研究采用 $\mathrm{Q}+\mathrm{K}$ 混合线性模型, 使用 $90 \mathrm{~K}$ SNP 芯片对 207 份国内外小麦品种(系)的整穗发芽率进 行全基因组关联分析, 获得 34 个显著关联的 SNP 标 记位点, 其中 $6 \mathrm{~B}$ 是携带穗发芽抗性基因的热点区域, 定位于 6B 染色体上的 wsnp_Ex_c14101_22012676 在 E1、E2 及平均环境下被共同检测到，对表型的贡献 率为 $5.86 \% \sim 11.61 \%$, 该位点可能是与小麦穗发芽抗性 相关的重要位点。将表型效应值大且能稳定遗传的 SNP 标记在普通小麦中国春基因组数据库中进行检索, 共 挖掘了 13 个最有可能与穗发芽抗性相关的候选基因。

\section{References}

[1] Zhou Y, He Z H, Chen X M, Wang D S, Yan J, Xia X C. Genetic improvement of wheat yield potential in north China. In: Wheat Production in Stressed Environments. Berlin: Springer Netherlands, 2007. pp 583-589.

[2] Zheng T C, Zhang X K, Yin G H, Wang L N, Han Y L, Chen L. Genetic gains in grain yield, net photosynthesis and stomatal conductance achieved in Henan province of China between 1981 and 2008. Field Crops Res, 2011, 122: 225-233.

[3] Xiao S H, Zhang X Y, Yan C S. Germplasm improvement for pre-harvest sprouting resistance in Chinese white-grained wheat: an overview of the current strategy. Euphytica, 2002, 126: 35-38.

[4] 于立河, 刘德福, 郭伟, 薛盈文, 曾玲玲, 张健, 侯海鹏. 收获 期降雨对春小麦品质的影响. 麦类作物学报, 2007，27: $658-660$.

Yu L H, Liu D F, Guo W, Xue Y W, Zeng L L, Zhang J, Hou H P. Effects of raining during harvest season on quality of spring wheat. J Triticeae Crops, 2007, 27: 658-660 (in Chinese with English abstract).

[5] 苏东民, 魏雪芹. 发芽对小麦及面粉品质的影响. 粮食科技与 经济, 2005, (6): 39-41.

Su D M, Wei X Q. Effect of germination on quality of wheat and flour. Grain Sci Technol Econ, 2005, (6): 39-41 (in Chinese with English abstract).

[6] Humphreys D G, Noll J. Methods for characterization of pre-harvest Sprouting resistance in a wheat breeding program. Euphytica, 2002, 126: 61-65.

[7] 王黎明, 李永霞, 高华利, 王春平, 王洪刚, 李兴锋. 小麦穗 发芽基因等位变异及其区域分布研究. 西北植物学报, 2019,
39(1): 52-58.

Wang L M, Li Y X, Gao H L, Wang C P, Wang H G, Li X L. Molecular identification and distribution of pre-harvest sprouting (PHS) genes in different common wheat regions of China. Acta Bot Boreali-Occident Sin, 2019, 39: 52-58 (in Chinese with English abstract).

[8] King R W, Richards R A. Water uptake in relation to pre-harvest sprouting damage in wheat: ear characteristics. Aust J Agric Res, 1984, 2: 55-63.

[9] Detje H. Effects of varying nitrogen rates on pre-harvest sprouting and $\alpha$-amylase activity in cereals. J Agron Crop Sci, 1992, 169: 38-45.

[10] 杨燕, 张春利, 何中虎, 夏兰芹. 小麦抗穗发芽研究进展. 植 物遗传资源学报, 2007, 8: 503-509.

Yang Y, Zhang C L, He Z H, Xia L X. Advances on resistance to pre-harvest sprouting in wheat. $J$ Plant Genet Resour, 2007, 8: 503-509 (in Chinese with English abstract).

[11] 王志龙, 于亚雄, 王志伟, 程加省, 乔祥梅, 杨金华. 小麦穗发 芽抗性鉴定及机制分析. 西南农业学报, 2016, 29: 2513-2519.

Wang Z L, Yu Y X, Wang Z W, Cheng J S, Qiao X M, Yang J H. Resistance and mechanism of pre-harvest sprouting in wheat. Southwest China J Agric Sci, 2016, 29: 2513-2519 (in Chinese with English abstract).

[12] 李玉营, 马东方, 王晓玲, 方正武. 小麦穗发芽鉴定方法的比 较与分析. 广西植物, 2016, 36: 245-248.

Li Y Y, Ma D F, Wang X L, Wang X L, Fang Z W. Comparison and analysis of wheat pre-harvest sprouting screening methods. Guihaia, 2016, 36: 245-248 (in Chinese with English abstract).

[13] 朱玉否, 王升星, 赵良侠, 张德新, 胡建帮, 曹雪连, 杨亚杰, 常成, 马传喜, 张海萍. 以关联分析发掘小麦整穗发芽抗性基 因分子标记.作物学报, 2014, 40: 1725-1732.

Zhu Y L, Wang S X, Zhao L X, Zhang D X, Hu J B, Cao X L, Yang Y J, Chang C, Ma C X, Zhang H P. Exploring molecular markers of pre-harvest sprouting resistance gene using wheat intact spikes by association analysis. Acta Agron Sin, 2014, 40: 1725-1732(in Chinese with English abstract).

[14] Munkvold J D, J, Tanaka J, Benscher D, Sorrells M E. Mapping quantitative trait loci for preharvest sprouting resistance in white wheat. Theor Appl Genet, 2009, 119: 1223-1235.

[15] Osa M, Kato K, Mori M, Shindo C, Torada A, Miura H. Mapping QTLs for seed dormancy and $V p 1$ homologue on chromosome 3A of wheat. Theor Appl Genet, 2003, 169: 1491-1496.

[16] Somyong S, Ishikawa G, Munkvold J D, Tanaka J, Benscher D, Cho Y G. Fine mapping of a preharvest sprouting QTL interval on chromosome 2B in white wheat. Theor Appl Genet, 2014, 127: 1843-1855.

[17] Tyagi S, Gupta P K. Meta-analysis of QTLs involved in pre-harvest sprouting tolerance and dormancy in bread wheat. TGG, 2012, 3: 9-24.

[18] Lin M, Cai S, Wang S, Liu S, Zhang G, Bai G. Genotyping-by-sequencing (GBS) identified SNP tightly linked to QTL for pre-harvest sprouting resistance. Theor Appl Genet, 2015, 128: 1385-1395.

[19] Liu S B, Cai S B, Robert G. Quantitative trait loci for resistance to pre-harvest sprouting in US hard white winter wheat. Theor Appl Genet, 2008, 117: 691-699. 
[20] Chen G F, Zhang H, Deng Z Y, Wu R G, Li D M, Wang M Y. Genome-wide association study for kernel weight-related traits using SNPs in a Chinese winter wheat population. Euphytica, 2016, 212: 173-185.

[21] Kulwal P, Ishikawa G, Benscher D, Feng Z, Yu L X, Jadhav A. Association mapping for pre-harvest sprouting resistance in white winter wheat. Theor Appl Genet, 2012, 125: 793-805.

[22] Jaiswal V, Mir R R, Mohan A, Balyan H S, Gupta P K. Association mapping for pre-harvest sprouting tolerance in common wheat (Triticum aestivum L.). Euphytica, 2012, 188: 89-102.

[23] Lin M, Zhang D, Liu S, Zhang G, Yu J, Fritz A K. Genome-wide association analysis on pre-harvest sprouting resistance and grain color in U.S. winter wheat. BMC Genome, 2016, 17: 794-801.

[24] Zhu Y L, Wang S, Wei W, Xie H, Liu K, Zhang C, Wu Z, Jiang H, Cao J, Zhao L, Lu J, Zhang H, Chang C, Xia X, Xiao S, Ma C. Genome-wide association study of pre-harvest sprouting tolerance using a 90K SNP array in common wheat (Triticum aestivum L.). Theor Appl Genet, 2019, 132: 2947-2963.

[25] Zuo J H, Lin C T, Cao H, Chen F Y, Liu Y X, Liu J D. Genome-wide association study and quantitative trait loci mapping of seed dormancy in common wheat (Triticum aestivum L.). Planta, 2019, 250: 187-198.

[26] Groos C, Gay G, Perretant R M. Study of the relationship between pre-harvest sprouting and grain color by quantitative trait loci analysis in a white red grain bread-wheat cross. Theor Appl Genet, 2002, 104: 39-47.

[27] Meng L, Li H, Zhang L, Wang J. QTL IciMapping: integrated software for genetic linkage map construction and quantitative trait locus mapping in biparental populations. Crop J, 2015 , 3:269-283.

[28] Wang S X, Zhu Y L, Zhang D X. Genome-wide association study for grain yield and related traits in elite wheat varieties and advanced lines using SNP markers. PLoS One, 2017, 12: 1-14.

[29] Zhu C S, Gore M, Buckler E S, Yu J M. Status and prospects of association mapping in plants. Plant Genome, 2008, 1: 5-20.

[30] Yu J M, Pressoir G, Briggs W H, Irie V, Yamasaki M, Doebley J F, McMullen M D, Gaut B S, Nielsen D M. A unified mixed-model method for association mapping that accounts for multiple levels of relatedness. Nat Genet, 2006, 38: 203-208.

[31] Marco M, Walid E F, Ghasemali N, Silvio S, Canè M A, Chiara C M. Prioritizing quantitative trait loci for root system architecture in tetraploid wheat. $J$ Exp Bot, 2016, 67: 1161-1178.

[32] Yang Y, Zhao X L, Xia L Q, Chen X M, Xia X C, He Z H. Development and validation of a viviparous-1, STS marker for pre-harvest sprouting tolerance in Chinese wheats. Theoret Appl Genet, 2007, 115: 971-980.

[33] Bi H H, Sun Y W, Xiao Y G, Xia L Q. Characterization of $D F R$ allelic variations and their associations with pre-harvest sprouting resistance in a set of red-grained Chinese wheat germplasm. Euphytica, 2014, 195: 197-207.

[34] Rasul G, Humphreys D G, Brûlé-Babel A, McCartney C A, Knox R E, Depauw R M. Mapping QTLs for pre-harvest sprouting traits in the spring wheat cross 'RL4452/AC Domain'. Euphytica, 2009, 168: 363-378

[35] Zhang C L, He X Y, He Z H, Wang L H, Xia X C. Cloning of Ta CYP707A1 gene that encodes ABA 8'-hydroxylase in common wheat (Triticum aestivum L.). Agric Sci China, 2009, 8: 902-909.

[36] Hucl P, Singh R, Matus-Cádiz M A, Bga M, Ravindra N. Identification of genomic regions associated with seed dormancy in white-grained wheat. Euphytica, 2010, 174: 391-408.

[37] Roy J K, Prasad M, Varshney R K, Balyan H S, Blake T K, Dhaliwal H S. Identifification of a microsatellite on chromosomes $6 \mathrm{~B}$ and a STS on 7D of bread wheat showing an association with preharvest sprouting tolerance. Theor Appl Genet, 1999, 99: 336-340.

[38] Gao F, Ayele B T. Functional genomics of seed dormancy in wheat: advances and prospects. Front Plant Sci, 2014, 5: 458-463.

[39] 刘莉, 王海庆, 陈志国. 小麦抗穗发芽研究进展. 作物杂志, 2013, (4): 6-11.

Liu L, Wang $\mathrm{H} \mathrm{Q}$, Chen $\mathrm{Z}$ G. Advances on resistance to pre-harvest sprouting in wheat. Crops, 2013, (4): 6-11 (in Chinese with English abstract).

[40] 朱冬梅, 张晓祥, 王玲, 方正武, 江伟, 张晓. 长江中下游麦 区主要小麦品种穗发芽抗性及鉴定方法比较. 麦类作物学报, 2014, 34: 944-949.

Zhu D M, Zhang X X, Wang L, Fang Z W, Jiang W, Zhang X. Resistance of pre-harvest sprouting of wheat cultivars planted in the valley of middle and lower reach of Yangtze River and comparison of the identification methods. J Triticeae Crops, 2014, 34: 944-949 (in Chinese with English abstract).

[41] 苗西磊, 王德森, 夏兰芹, 张运宏, 王忠伟, 何中虎, 陈新民. 白粒小麦品种(系)穗发芽抗性机制分析. 麦类作物学报, 2011, 31: 741-746.

Miao X L, Wang D S, Xia L X, Zhang H Y, Wang Z W, He Z H, Chen X M. Analysis on the mechanism of pre-harvest sprouting resistance in white-grain wheat. $J$ Triticeae Crops, 2011, 31: 741-746 (in Chinese with English abstract).

[42] Warner R L, Kudrna D A, Spaeth S C, Jones S S. Dormancy in white-grain mutants of Chinese spring wheat (Triticum aestivum L.). Seed Sci Res, 2000, 10: 51-60.

[43] Nielsen M T, McCrate A J, Heyne E G, Paulsen G M. Effect of weather variables during maturation on pre-harvest sprouting of hard white wheat. Crop Sci, 1984, 24: 779-782.

[44] Osanai S I, Amano Y, Mares D. Development of highly sprouting tolerant wheat germplasm with reduced germination at low temperature. Euphytica, 2005, 143: 301-307.

[45] Mares D J. Temperature dependence of germinability of wheat grain in relation to pre-harvest sprouting. Aust J Agric Res, 1984, 35: $115-128$.

[46] Bailey P C, McKibbin R S, Lenton J R, Holdsworth M J, Flintham J E, Gale M D. Genetic map locations for orthologous Vp1 genes in wheat and rice. Theor Appl Genet, 1999, 98: 281-284.

[47] 王焕雪. 小麦穗发芽抗性基因的全基因组关联分析及等位变 异发掘. 北京农学院硕士学位论文, 北京, 2019.

Wang H X. Genome Wide Association Analysis and Allelic Variation of Wheat Pre-Harvest Sprouting Resistance Genes. MS Thesis of Beijing University of Agriculture, Beijing, China, 2019 (in Chinese with English abstract).

[48] 张海萍, 常成, 肖世和. 小麦胚休眠中 ABA 信号转导的蛋白 质组分析. 作物学报, 2006, 5: 690-697.

Zhang H P, Chang C, Xiao S H. Proteomic analysis on abscisic acid signal transduction in embryo dormancy of wheat (Triticum aestivum L.). Acta Agron Sin, 2006, 5: 690-697 (in Chinese with 
English abstract).

[49] 吴丹, 唐冬英, 李新梅, 李丽, 赵小英, 刘选明. F-box 蛋白在植物 生长发育中的功能研究进展. 生命科学研究, 2015, 19: 362-367.

Wu D, Tang D Y, Li X M, Li L, Zhao X L, Liu X M. Research progress on the function of F-box protein in plant growth and development. Life Sci Res, 2015, 19: 362-367 (in Chinese with English abstract).

[50] 张华. 外源一氧化氮促进小麦种子萌发及其信号作用机制研
究. 南京农业大学硕士学位论文, 江苏南京, 2005 .

Zhang H. Exogenous Nitric Oxide Promotes Wheat Seed Germination and Its Signaling Mechanism. MS Thesis of Nanjing Agricultural University, Nanjing, Jiangsu, China, 2005 (in Chinese with English abstract).

[51] Himi E, Maekawa M, Miura H, Noda K. Development of PCR markers for Tamyb10 related to $R-1$, red grain color gene in wheat. Theor Appl Genet, 2012, 122: 1561-1576.

更正 : 马娟等发表在本刊 2020,46(3): 385-394 的论文《利用 WGCNA 鉴定玉米株高和穗位高基因共表达模 块》中的图 1B 更正如下。

\section{原图}
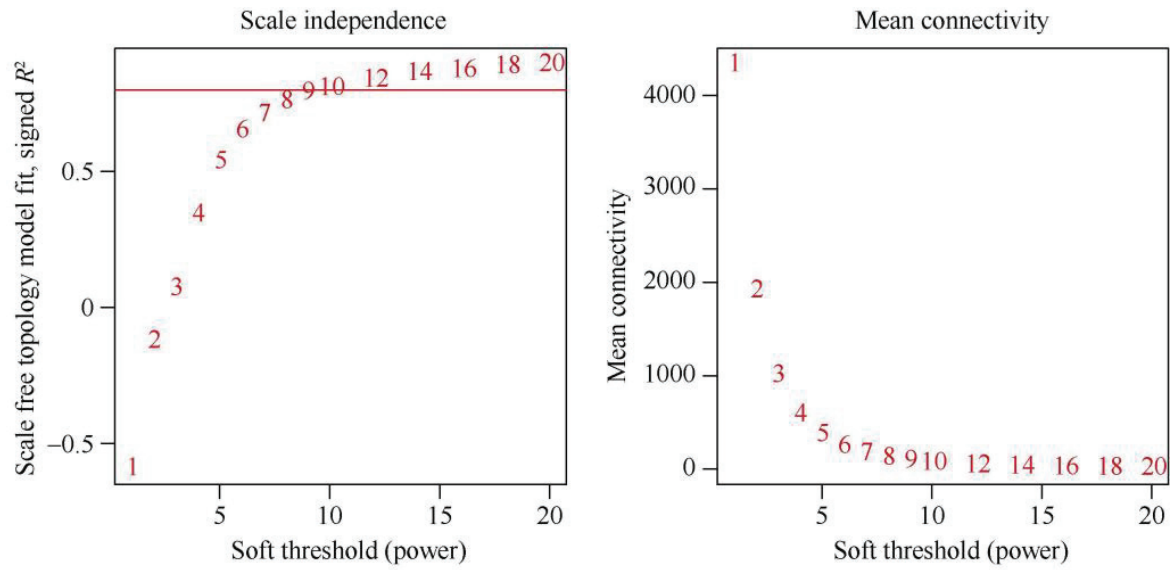

\section{更正为}
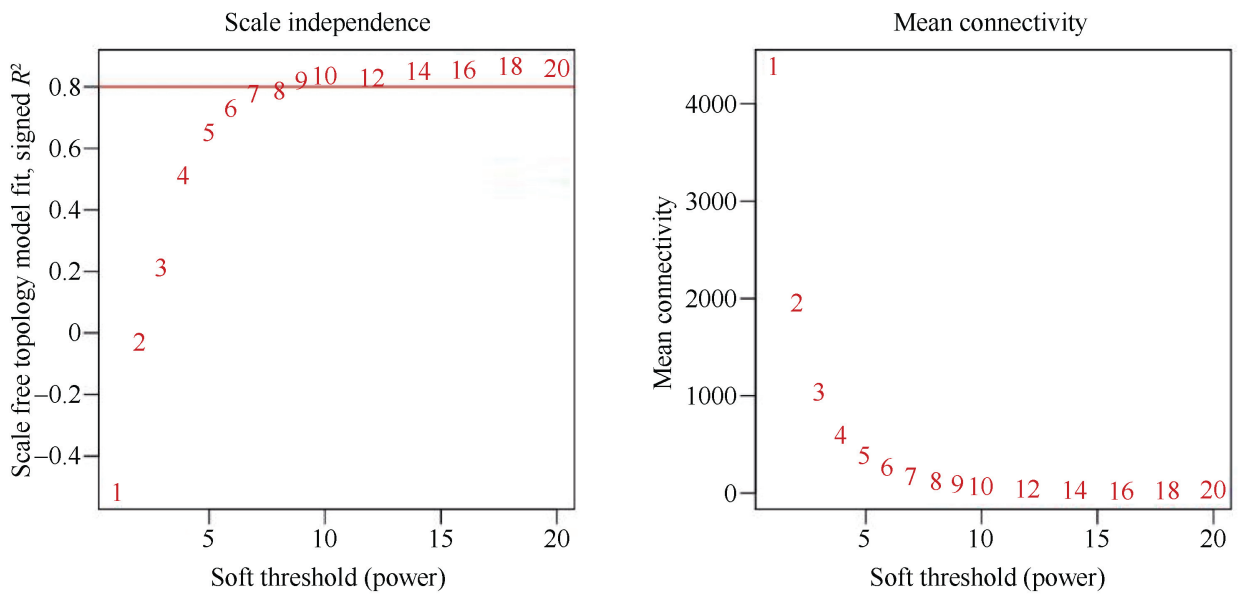